\title{
Antibody Against Nerve Growth Factor-inducible Large External (NILE) Glycoprotein Labels Nerve Fiber Tracts in the Developing Rat Nervous System ${ }^{1}$
}

\author{
WILLIAM B. STALLCUP, ${ }^{2}$ LORA L. BEASLEY, AND JOEL M. LEVINE ${ }^{3}$ \\ La Jolla Cancer Research Foundation, La Jolla, California 92037
}

\begin{abstract}
The NILE (nerve growth factor-inducible large external) glycoprotein is a 230,000 -dalton molecule found on the surface of PC12 cells. Immunologically cross-reactive glycoproteins in the molecular weight range of 215,000 to 230,000 have been found on many types of neurons in culture. Using immunohistochemical methods, we have shown that NILErelated glycoproteins are present in neuronal fiber tracts of the developing rat brain. Antibody against the NILE glycoprotein specifically labels processes that appear identical to those recognized by antibodies against the neurofilament triplet of proteins. These processes are clearly distinct from the radial glial fibers recognized by antibody against the intermediate filament protein vimentin. NILE glycoprotein is not distributed uniformly over the entire neuronal surface but is concentrated on neurites and is much less abundant on cell bodies. NILE-positive fiber tracts are first seen in the spinal cord and rhombencephalon on embryonic day 11 and over the next 2 days appear in the mesencephalon and diencephalon. Staining in the telencephalon is not seen until embryonic day 15. The appearance of NILE immunoreactivity in these various regions closely parallels the appearance of neurofilament polypeptides, suggesting that NILE-related glycoproteins are present during the early phases of fiber tract formation. This idea is supported by the finding that the NILE glycoprotein can be found postnatally in parts of the nervous system such as the cerebellar cortex and olfactory bulb which undergo major histogenesis during the postnatal period. In the cerebellum the appearance of NILE immunoreactivity in the two major fiber zones, the molecular layer and the white matter, parallels the development of the fiber structure of these layers. These findings support tissue culture studies which suggest a role for the NILE glycoprotein in mediating nerve fiber fasciculation.
\end{abstract}

Received June 21, 1984; Revised September 27, 1984;

Accepted September 28, 1984

\footnotetext{
${ }^{1}$ We are especially grateful to Drs. Brent Stanfield and David Schubert for their many helptul suggestions regarding the manuscript and to Luann Teschmacher for her technical assistance. This research was supported by National Institutes of Health Grant NS 16112 and a Muscular Dystrophy Association grant to W. B. S., and by a Muscular Dystrophy Association postdoctoral fellowship to J. M. L. Portions of this work were carried out at the Salk Institute for Biological Studies.

${ }^{2}$ To whom correspondence should be sent.

${ }^{3}$ Present address: Department of Neurobiology and Behavior, State University of New York at Stony Brook, Stony Brook, NY 11794.
}

Neuronal cell surface molecules are of interest because of their role as receptors for neurotransmitters, because of their possible involvement in cell-cell recognition and interaction, and because of their usefulness as markers for tracing the development of neurons during the maturation of the nervous system. We have been interested in a family of glycoproteins found on the surfaces of rat and mouse neurons. The best characterized of these glycoproteins is the 230,000-dalton nerve growth factor-inducible large external (NILE) glycoprotein which is expressed on the surface of PC12 cells (McGuire et al., 1978; Lee et al., 1981; Salton et al., 1983a, b). Immunologically cross-reactive glycoproteins in the molecular weight range of 215,000 to 230,000 are found not only on other neuronal cell lines but also on neurons in primary culture (Akeson and Hsu, 1978; Salton et al., 1983a; Stallcup et al., 1983). The biochemical differences between the NILE-related glycoproteins expressed by different types of neurons are just beginning to be explored (Salton et al., 1983b; Stallcup and Beasley, 1985b).

Antibodies against the NILE glycoprotein have proved useful not only for biochemical studies of this family of neuronal glycoproteins, but also for immunohistochemical identification of neuronal cells in primary culture and for studies on the function of the molecule. In cultures of central nervous system tissue, astrocytes, oligodendrocytes, and fibroblasts do not express a NILE-related component, so that anti-NILE antibodies can be used in these cultures as specific probes for neurons (Stallcup et al., 1983). Our immunofluorescence experiments suggest to us that NILE-like glycoproteins are preferentially expressed on neurites, rather than on cell bodies, in these cultures (Stallcup et al., 1983). Moreover, Fab' fragments of antiNILE antibodies are very effective in blocking the formation of neurite bundles in primary cultures of embryonic rat brain, suggesting a role for NILE-related glycoproteins in neurite fasciculation (Stallcup and Beasley, 1985a).

We have extended our investigations of the NILE glycoprotein by using immunohistochemical methods to localize NILE-related molecules in the developing rat brain. We report that NILE-related components are found on neurons in vivo and that the early phases of development of neuronal fiber tracts can be traced by means of immunofluorescent staining with anti-NILE antibody.

\section{Materials and Methods}

Antisera. Our anti-NLE antisera were prepared as described previously (Stallcup et al., 1983). The IgG fractions of antisera raised against nerve growth factor (NGF)-treated PC12 cells (Greene and Tischler, 1976) were absorbed exhaustively with three non-neuronal cell lines, B9, B92 (Schubert et al., 1974), and PCG2 (Goodman and Herschman, 1978), and with rat adrenal tissue. Both rabbit anti-NILE (RaNILE) and guinea pig anti-NILE (GPaNILE) were prepared in this way. These absorbed antisera specifically immunoprecipitate the 215,000-to 230,000-dalton NILE-related glycoproteins from a variety of neuronal cell types (Stallcup and Beasley, 1985a). In a few experiments we have observed a very minor glycoprotein component in the range of 150,000 to 170,000 daltons which is immunoprecipitated by our 
antibody. The fact that this minor component is not consistently found in our immunoprecipitates and the fact that similar components are occasionally seen in immunoprecipitation experiments with an antibody raised against purified NILE glycoprotein (Salton et al., 1983a) lead us to suspect that this material may be related to the NILE glycoprotein, possibly as a partially degraded form of NILE.

Rabbit antibody against neurofilament proteins (RaNF) was generously provided by Dr. Doris Dahl. This antibody appears to recognize all three members $(200,000,150,000$, and 70,000 daltons $)$ of the triplet of neurofilament polypeptides (Dahl, 1981). Rabbit anti-vimentin (RaVim) was a gift from Dr. Jonathan Singer. The derivation and characterization of mouse monoclonal anti-D1.1 have been described (Levine et al., 1984). Monoclonal antiF84.I antibody resulted from the immunization of a BALB/C mouse with the neuronal XKM cell line (Bulloch et al., 1977). The characterization of this antibody will be described elsewhere. The following fluorescent secondary antibodies were also used in this study: fluorescein-labeled goat anti-mouse immunoglobulin ( $\mathrm{F}$-GaMlg) (Tago), fluorescein- and rhodamine-labeled goat anti-rabbit immunolobulin ( $\mathrm{F}-\mathrm{GaRlg}$ and $\mathrm{R}-\mathrm{GaRlg}$ ) prepared from antibody affinity purified in our laboratory, and fluorescein-labeled goat anti-guinea pig immunoglobulin (F-GaGPIg) prepared using antibody purchased from CalBiochem. The secondary antisera were used for both single- and doublelabel experiments according to the protocol outlined in Table I.

Immunohistochemistry. Sprague-Dawley rat embryos and pups were used for these studies. Timed pregnant females were obtained from Zivic Laboratories. Embryonic tissues to be examined were fixed by immersion for $6 \mathrm{hr}$ in cold $1 \%$ paraformaldehyde buffered at $\mathrm{pH} 7.2$ with $0.1 \mathrm{M}$ sodium phosphate, followed by overnight immersion in this same fixative containing $20 \%$ sucrose. When monoclonal anti-D1.1 was to be used, the fixation procedure was modified by the addition of $0.1 \%$ glutaraldehyde to the solution. Ten- to 12-day-old embryos were fixed whole, but with older embryos the brains were removed for fixation. The spinal cords of these older embryos were exposed in situ for fixation by removing the overlying tissue. Postnatal

TABLE I

Primary and secondary antibodies used for immunofluorescence

This table shows the combinations of primary and secondary antibodies that were used in the experiments described in this paper.

\begin{tabular}{cll}
\hline Experiment & \multicolumn{1}{c}{ Primary Antisera } & Secondary Antisera \\
\hline 1 & RaNILE & F-GaRlg \\
2 & RaNILE + MaD1.1 & R-GaRlg + F-GaMlg \\
3 & RaNILE + MaF84.1 & R-GaRig + F-GaMlg \\
4 & GPaNILE + RaNF & F-GaGPIg + R-GaRig \\
5 & GPaNILE + RaVim & F-GaGPlg + R-GaRlg \\
\hline
\end{tabular}

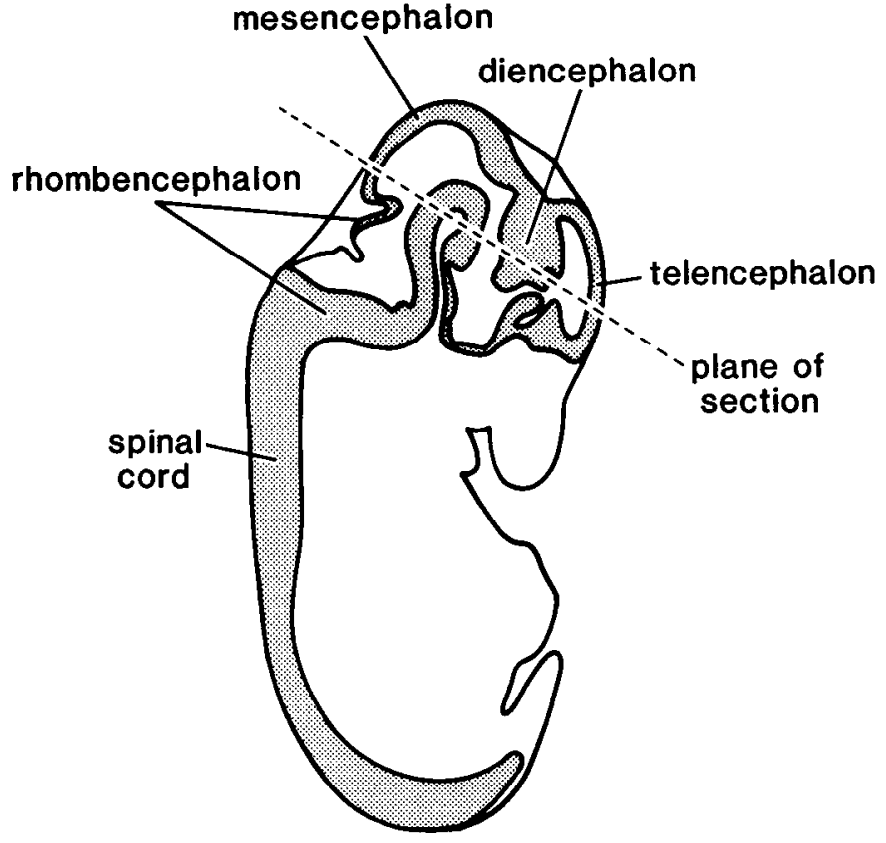

Figure 1. Sagittal view of the E14 rat. The brain sections used for our studies were cut in a horizontal plane, as illustrated by the dashed line. animals were perfused through the heart with $1 \%$ paraformaldehyde, $\mathrm{pH} 7.2$. Brains were removed and postfixed overnight in the same fixative containing $20 \%$ sucrose. Fixed tissues were frozen in OCT compound and $15-\mu \mathrm{m}$ sections were cut on a Lab Tek II cryostat microtome. Sections of spinal cord were cut in a transverse orientation. Brains were sectioned in the horizontal orientation shown in Figure 1. Sections were mounted on gelatincoated slides.

For immunofluorescent staining, sections were incubated overnight at $4^{\circ} \mathrm{C}$ with a primary antiserum or a combination of two primary antisera) diluted in potassium phosphate-buffered saline, $\mathrm{pH} 7.4$, containing $2 \%$ normal goat serum and $0.1 \%$ Triton X-100 (KPBS-NGS-TX). After two 5 -min washes in KPBS-NGS-TX, the slides were incubated for $1 \mathrm{hr}$ at room temperature with the fluorescent secondary antiserum diluted in KPBS-NGS (see Table I for a list of secondary antisera used). Following two more washes in KPBS-NGS and a third wash in distilled water, slides were coverslipped in glycerol and examined using a Zeiss microscope equipped for epifluorescence.

\section{Results}

Development of NILE-positive fiber tracts in the rat nervous system. NILE immunoreactivity is first detectable in the rat nervous system on embryonic day 11 (E11) in the ventral portions of the spinal cord and rhombencephalon (hindbrain). We will first describe the changes in staining seen with anti-NILE antibody in the spinal cord during the days following E11 and then present a parallel description of the development of NILE immunoreactivity in the brain.

Immunofluorescent staining with anti-NILE in the E11 and E12 spinal cord is restricted to the marginal layer of the ventral and lateral funiculi where fiber tracts first develop (Fig. 2B). The spinal nerves, spinal ganglia, and dorsal roots are also stained at E11 and E12, but there is only a very small area of staining at the point where the dorsal rootlets enter the spinal cord. At this early stage the dorsal root entry zone is located ventral and lateral relative to its position in the adult cord. At E13 and E14 the staining in the ventral funiculi is more intense and covers a broader area than at E11 and E12. AntiNILE staining of the dorsal root entry zones is not only much more ciistinct at $E 13$ and $E 14$, but also occupies a more dorsolateral position (Fig. 2, C and D). By E16 the staining of the dorsal root entry zones and the dorsal funiculi is very intense across the entire dorsal surface of the cord (Fig. $2 E$ ), and by E18 the staining has been extended into the gray matter medial to the dorsal horns (Fig. $2 F$ ). There is also continued bright staining of the lateral and ventral funiculi at E18. During the first few days after birth, staining of the spinal cord with anti-NILE anlibody becomes progressively weaker. Although no single cutoff day can be pinpointed, staining is very difficult to detect by the end of the first week postnatally.

Other structures associated with the spinal cord are also stained by the anti-NILE antibody. Figure 2, $B$ and $D$ shows that the dorsal roots and dorsal root ganglia are NiLE positive. The higher power view in Figure 2, $G$ and $H$, shows that staining in a dorsal root ganglion is confined to nerve fibers. The cell bodies of neurons in the ganglion are not visibly labeled by the antibody. Figure 2, $G$ and $H$, also shows anti-NILE staining of the ventral root. Not shown are the spinal nerves and sympathetic ganglia which are also NILE positive.

In the rhombencephalon at E11 the labeling with anti-NILE antibody is quite similar to that in the E11 spinal cord in that the staining is confined to small bright patches within the marginal layer just beneath the pial surface (Fig. 3B). No staining is found in the mesencephalon (midbrain) or the diencephalon and telencephalon (forebrain) at this time. At E12 the NILE immunoreactivity in the marginal layer of the rhombencephalon is more extensive (Fig. $3 E$ ), but staining is still absent in the mesencephalon. In the ventral part of the forebrain there is a very small area of staining in the marginal layer of the dicephalon (not shown), but no staining is found in the telencephalon (Fig. $3 H$ ).

By E13 the anti-NILE staining in the rhombencephlon is more extensive, and a new area of staining is now found in the intermediate zone of the mesencephalon. In the forebrain there is an enlarged area of staining in the anterior diencephalon but no staining in the 

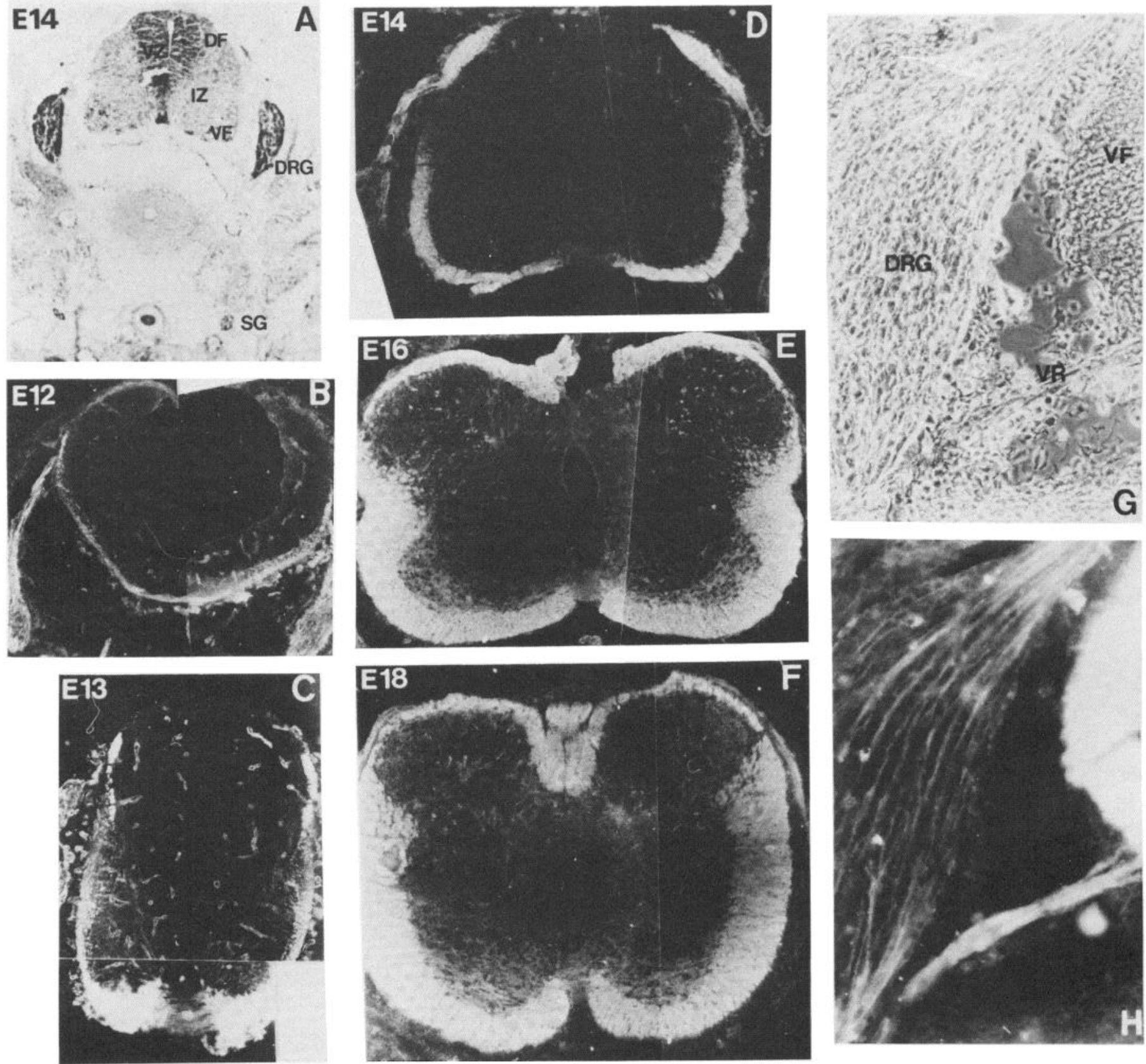

Figure 2. Immunofluorescent staining with anti-NILE antibody in transverse sections of the embryonic rat spinal cord. $A$, Nissl-stained section of embryonic day 14 spinal cord showing the major features of the tissue. $B$, embryonic day $12 ; C$, embryonic day $13 ; D$, embryonic day $14 ; E$, embryonic day $16 ; F$, embryonic day 18. G and $H$, Embryonic day 14 dorsal root ganglion with phase $(G)$ and RaNILE $(H)$. Nerve fibers running through the ganglion are stained by anti-NILE, but neuronal cell bodies within the ganglia are not. DF, dorsal funiculus; DRG, dorsal root ganglion; IZ, intermediate zone; SG, sympathetic ganglion; $V F$, ventral funiculus; $V R$, ventral root; $V Z$, ventricular zone.

telencephalon except for the olfactory nerves which lie on the anterior surface of the forebrain (not shown). The telencephalon remains unstained at E14 (Fig. 4D), although the distribution of NILE immunoreactivity in the rhombencephalon, mesencephalon, and diencephalon has become more extensive than E13 (Fig. 4, B and C).

E15 marks the initial appearance of anti-NILE staining in the telencephalon. Stained fibers can be seen in the marginal layer around the whole circumference of the telencephalon. In the most ventral portions of the telencephalon the internal capsule and cerebral peduncle can also be identifed as being positive for NILE immunoreactivity (not shown).

In the E16 brain the brightly stained telencephalic fiber tracts no longer occupy the marginal zone, but now occupy an intermediate position deep to the cells of the developing cortical plate. The NILEpositive fibers of this intermediate zone represent the developing deep white tract, and at more ventral levels of the forebrain stained fibers can be seen entering the ganglionic eminence to form the internal capsule and the cerebral peduncle (Fig. $5 B$ ). Figure $5, C$ to $H$, shows in more detail the development of anti-NILE staining in the deep white tract in the anterior telencephalon. At E14 no stained fibers are visible. At E15 stained fibers occupy the marginal zone. At E16 the developing cortical plate covers the NILE-positive fibers. Structures stained in the telencephalon of the E18 brain appear basically identical to those seen at E16 except that the fiber bundles are thicker, especially in the internal capsule. Staining in the E18 rhombencephalon, mesencephalon, and diencephalon appears to be only slightly more extensive than at E14 (not shown). 

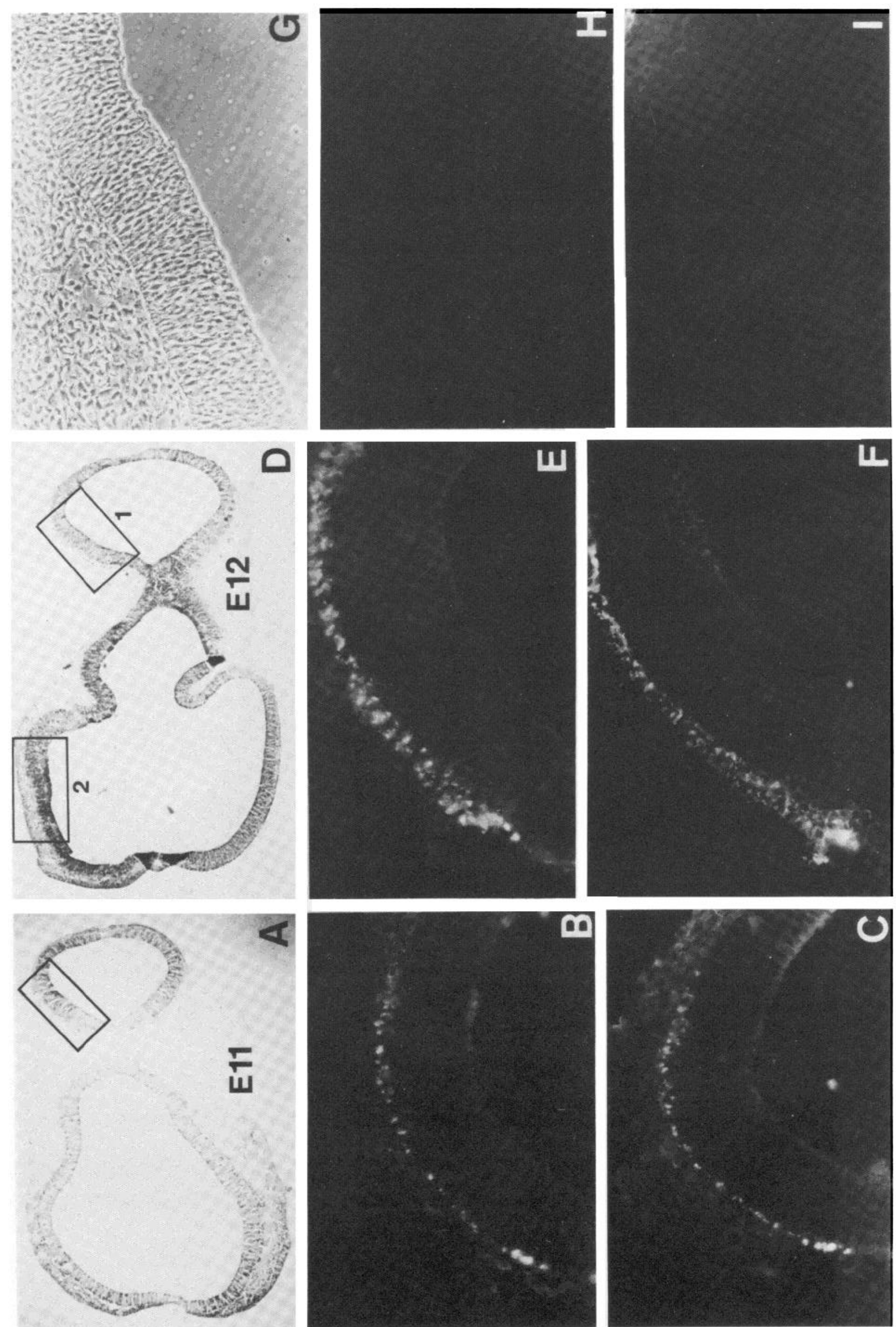
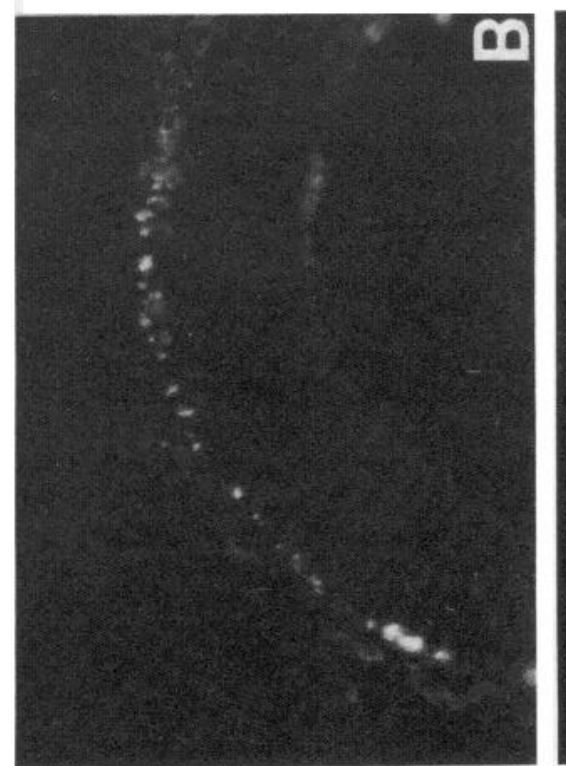

U.

क्षे

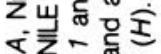
的

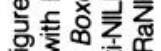

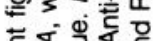

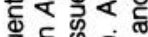
응

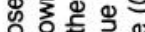

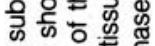
등 क

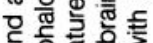
\% 용 \%

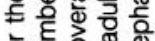
흥ㅇㅇㅇㅛ 능 造

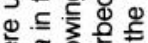
\$ \& क की क 흥하룽 语 。․ 등 흐을 है क 0 등은 西 등 票 क ठ क्ष 둥 중 क क ए人) 은 은 还 क舟的 记出 क 우을

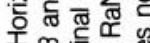

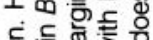
든드 녛 萐 등

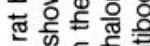
드는 흥 \% तิ

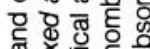
자을 $=80$ 不实 은 0 造足 을.

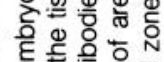

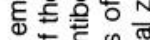
핟ㄷㄴ

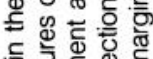
$\subseteq$ 正 山

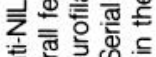

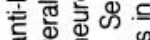
का

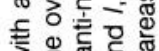
उ 을ㅁㄷㄴ

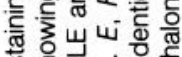
क्ष 击

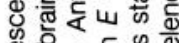
这 $\subseteq 0$ O등 릉

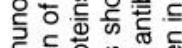

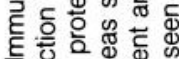
Eᄐ. ल

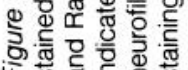



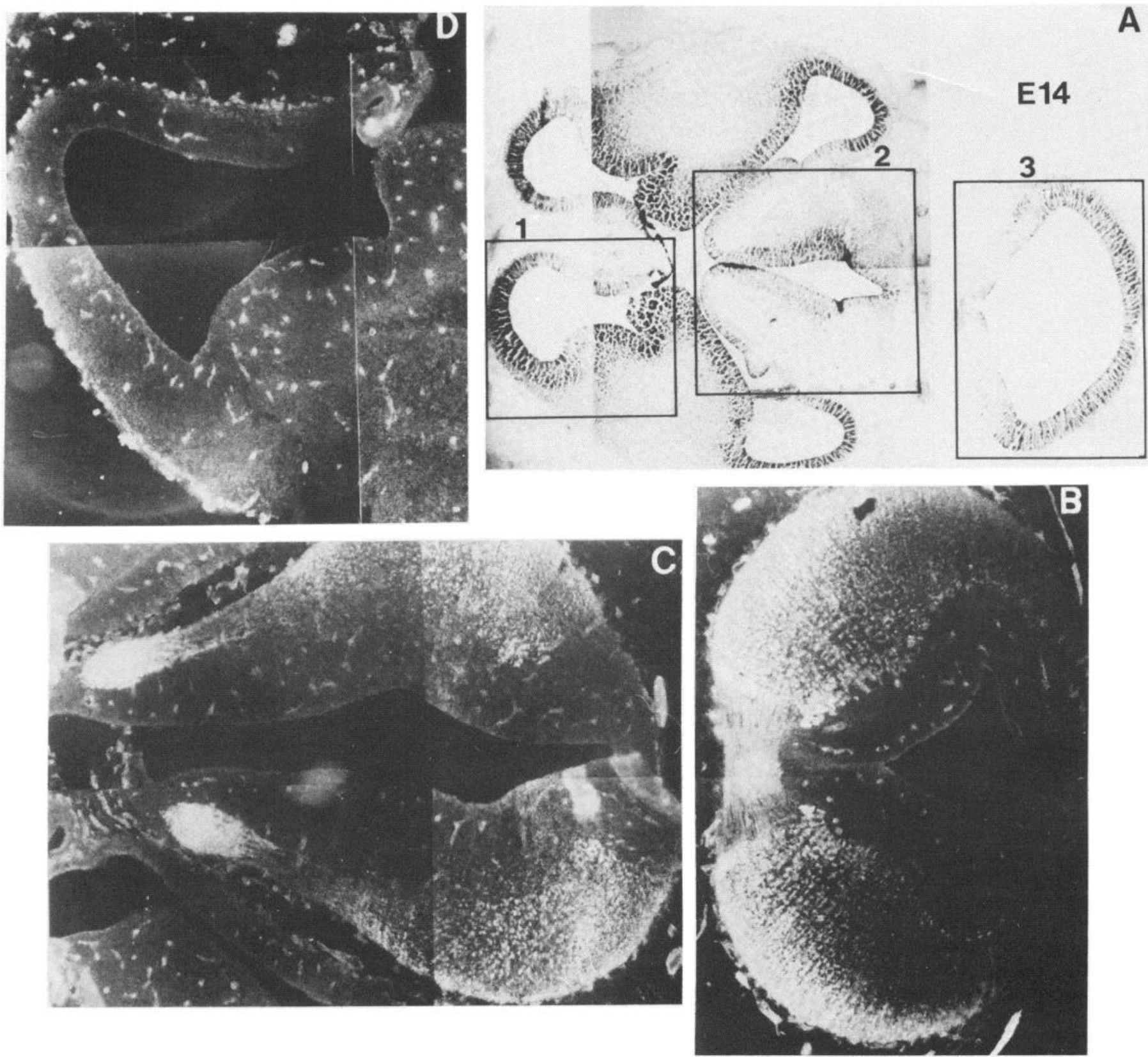

Figure 4. Immunofluorescent staining with anti-NILE in E14 rat brain. $A$, Nissl-stained section of $\mathrm{E} 14$ brain showing the general features of the tissue. Boxes 1,2, and 3 indicate areas shown in $B$ to $D . B$, Area 3 in the rhombencephalon with RaNILE. Extensive immunoreactivity is seen in the marginal and intermediate zones of the rhombencephalon. $C$, Area 2 in the diencephalon with RaNILE. Bright staining is found in the marginal and intermediate zones of the diencephalon. $D$, Area 1 in the telencephalon with RaNILE. No NILE glycoprotein is found in the E14 telencephalon.

As in the spinal cord, staining with anti-NILE in the postnatal brain becomes increasingly weaker. Little specific labeling can be seen by the end of the first week after birth. The major exceptions to this generalization are the cerebellum and olfactory bulb. At postnatal day $7(\mathrm{P} 7)$, staining with anti-NILE is seen in two regions of the cerebellum: (1) the molecular layer (Fig. 6, $A$ to $C$ ), which is densely packed with the parallel fibers of granule neurons, the dendrites of Purkinje cells, and the processes of stellate and basket neurons, and (2) the white matter, which contains several types of afferent axons and the efferent axons of Purkinje neurons. NILE immunoreactivity is present in the white matter by P2 (we did not examine earlier specimens) and disappears during the 5 th and 6 th weeks postnatally (Fig. 7). Staining of the molecular layer can be seen at P7 and, curiously enough, persists into adulthood (Fig. 7). In the olfactory bulb at P7 (Fig. 6, $D$ to $F$ ), staining with anti-NILE is found in the outermost layer occupied by the incoming olfactory nerve fibers, in the glomeruli, in the internal plexiform layer, and in the granule layer which contains the other major afferent and efferent fiber tracts of the bulb that interconnect with the rest of the brain (Shepherd, 1972).

Specificity of anti-NILE antibody for nerve fiber tracts. Several types of experiments were done to assess the specificity of the antibody against the NILE glycoprotein. One important control was to absorb RaNILE with homogenized adult rat brain tissue. This absorbed antibody failed to stain fiber tracts in rat brains of all ages tested. An example of E12 rhombencephalon is shown in Figure 3I. Anti-NILE absorbed with P12 cells also failed to stain fiber tracts in any of the sections tested (not shown). Nonspecific staining of the pia and blood vessels was seen with both anti-NILE and anti-NILE absorbed with brain tissue or PC12 cells. 

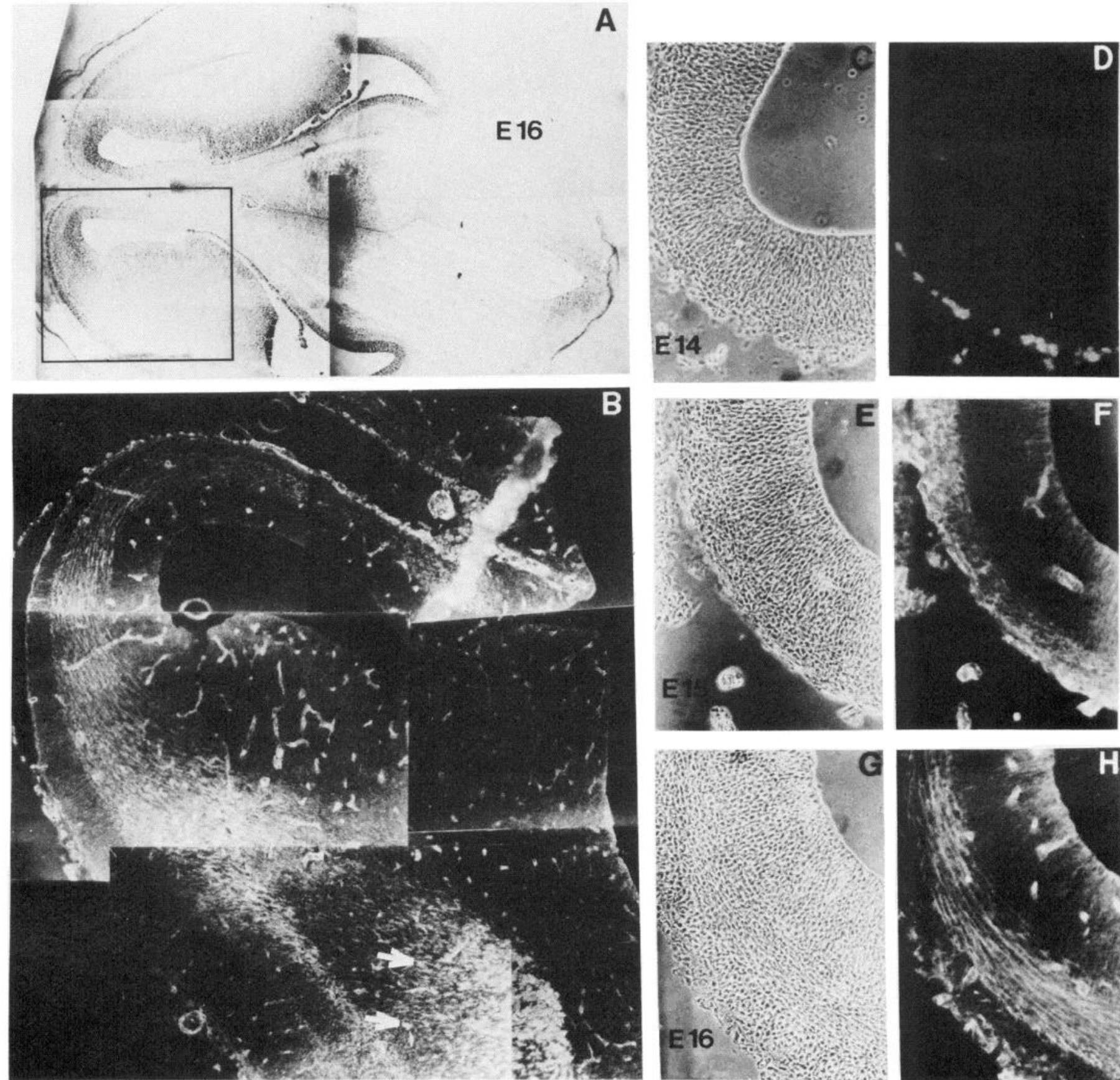

Figure 5. Immunofluorescent staining with anti-NILE in E16 rat brain. A, Nissl-stained section of E16 brain showing the overall features of the tissue. The box indicates the area shown in $B$. $B$, Boxed area in telencephalon shown in $A$, with RaNILE. NILE-positive fibers in the intermediate zone form the developing deep white tract. At the bottom right (double arrows) the fibers enter the ganglionic eminence to form the internal capsule. Notice that the fibers change their orientation in the internal capsule and begin to run perpendicular to the plane of sectioning as they descend toward the cerebral peduncle. $C$ to $H$, More detailed analysis of the development of NILE-positive fibers in the telencephalon. $C$ and $D$. Anterior telencephalon at E14 with phase (C) and RaNILE $(D)$. This reinforces the point made in Figure $4 D$ that the telencephalon is unstained at $E 14 . E$ and $F$, Anterior telencephalon at $E 15$ with phase $(E)$ and RaNILE $(F)$. NILE-positive fibers occupy the marginal zone of the E15 telencephalon. $G$ and $H$, Anterior telencephalon at E16 with phase $(G)$ and RaNILE $(H)$. NILE positive fibers occupy the intermediate zone, having been overlaid by cells of the developing cortical plate.

We also compared the anti-NILE staining with the staining obtained with antibodies of differing specificities. We stained serial sections of E11 and E12 rat brain with RaNILE and RaNF. Figure $3, B$ and $C$ and $E$ and $F$, shows that in both the $E 11$ and $E 12$ brains the two antisera stain the same areas in the marginal zone of the rhombencephalon. In addition to staining of serial sections we also did immunofluorescent double-staining of the same section using GPaNILE and RaNF. Figure $8, D, E$, and $F$, shows that these two antibodies give identical patterns of staining in the E14 rhomben- cephalon. This co-staining with the anti-NILE and anti-neurofilament antibodies was also found in other areas of the E14 brain as well as in brains of other ages.

In contrast, double-labeling with anti-NILE antibody and anti-vimentin, which reacts with the intermediate filament protein of immature radial astrocytes (Schnitzer et al., 1981; Bignami et al., 1982), results in two distinctly differing staining patterns (Fig. $8, B$ and $C$ ). In our horizontal sections the anti-NILE-reactive nerve fiber tracts run perpendicular to the plane of sectioning so that they are seen in 

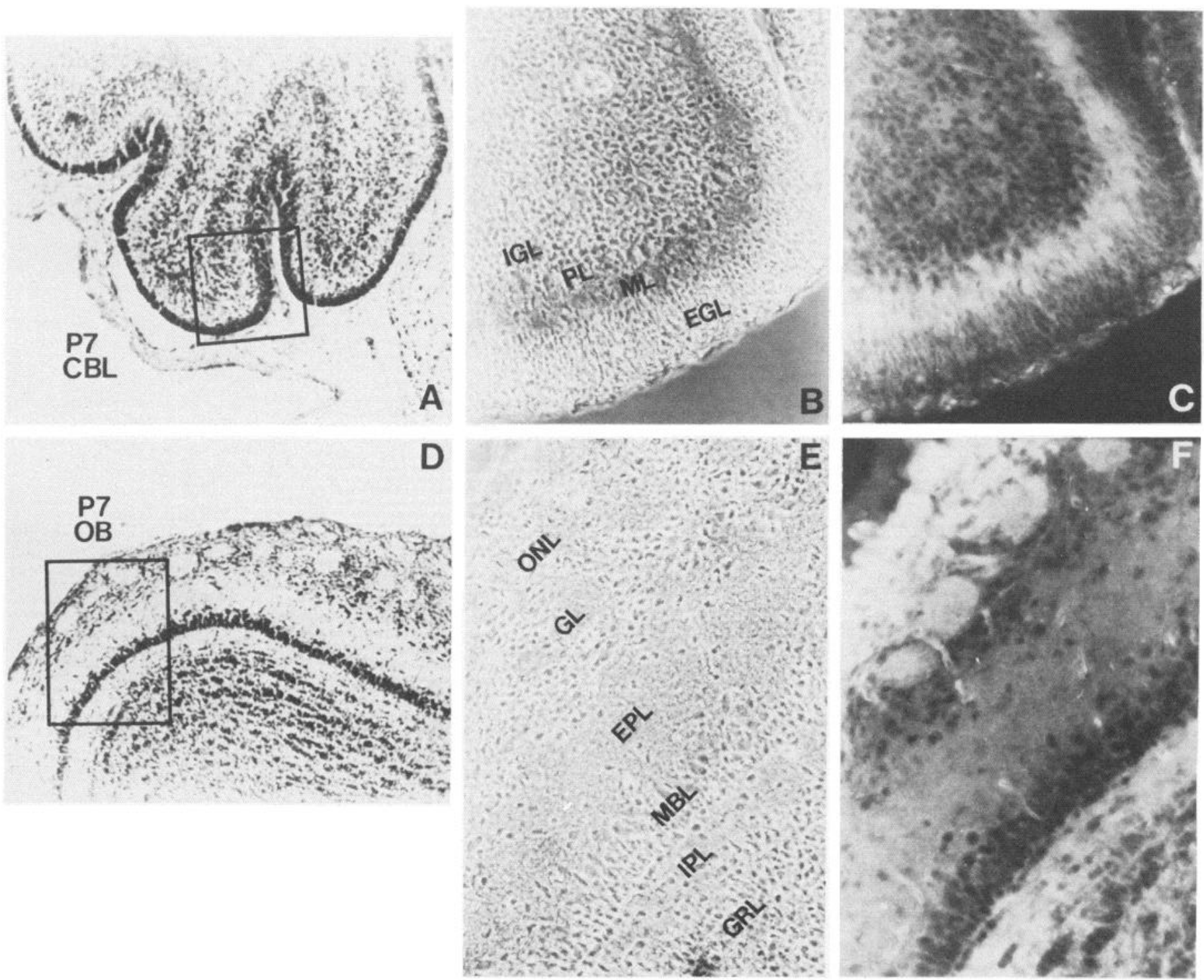

Figure 6. Immunofluorescent staining with anti-NILE in the P7 cerebellum and olfactory bulb. $A$, Nissl-stained section of P7 cerebellum showing the general features of the tissue. The box indicates the area shown in the photomicrographs in $B$ and $C$. $B$ and $C$, Folium of $P 7$ rat cerebellum treated with RaNILE. In this micrograph staining is confined largely to the molecular layer, although an expanded field would show additional staining in the white matter (see Fig. 7) $D$, Nissl-stained section of P7 olfactory bulb. The box indicates the area shown in the photomicrographs in $E$ and $F$. $E$ and $F, P 7$ rat olfactory bulb treated with RaNILE. Staining is not seen in areas occupied by cell bodies but is present in the olfactory nerve layer, the glomeruli, the internal plexiform layer and the granule layer. CBL, cerebellum; EGL, external granule cell layer; $E P L$, external plexiform layer; GL, glomerular layer; GRL, granule cell layer; IGL, internal granule cell layer; IPL, internal plexiform layer; $M B L$, mitral cell body layer; $M L$, molecular layer; $O N L$, olfactory nerve layer; $P L$, Purkinje cell layer.

cross-section, whereas the vimentin-reactive radial glial fibers run parallel to the plane of sectioning and are seen in a longitudinal orientation. The anti-D1.1 antibody, which recognizes a ganglioside present on neuroepithelial stem cells (Levine et al., 1984), stains the germinal cells lining the ventricular surfaces, an area distinct from the marginal and intermediate zones occupied by the NILE-positive nerve fiber tracts (Fig. 8, G to I).

Interestingly, although anti-NILE stains nerve fiber bundles quite well, it seems to be very poor at labeling nerve cell bodies and individual axonal processes. Figure $8, J$ to $L$ shows that in the E14 spinal cord anti-NILE intensely stains the fiber tracts in the ventral and lateral funiculi of the cord as well as the fasciculated fibers emerging from the cord in the ventral root. However, the cell bodies and processes of motor neurons located more medially in the ventral horn, identified by staining with monoclonal anti-F84.1, are not labeled by anti-NILE. A similar observation was made in the case of the dorsal root ganglion. The cell bodies of sensory neurons packed within the ganglion are not stained by anti-NILE, whereas the fibers that project from these cells and exit from the ganglion are NILE positive (Fig. 2, $G$ and $H$ ).

\section{Discussion}

The NILE-related glycoproteins comprise a family of 215,000 - to 230,000-dalton molecules which are found on all neuronal cell types that have been examined in tissue culture (Salton et al., 1983a; Stallcup et al., 1983). Of particular interest for our present discussion concerning NILE in the developing rat brain is the fact that NILErelated glycoproteins of about 215,000 daltons are expressed on neurons in cultures of E14 rat brain, E14 rat spinal cord, and P5 rat cerebellum (Salton et al. 1983a; Stallcup et al., 1983; Stallcup and Beasley, 1984a). Preliminary studies using Western blotting techniques indicate that a single band of this same size is recognized by anti-NILE antibody in extracts of E14 rat brain (data not presented). It has been demonstrated that a single NILE-immunoreactive 

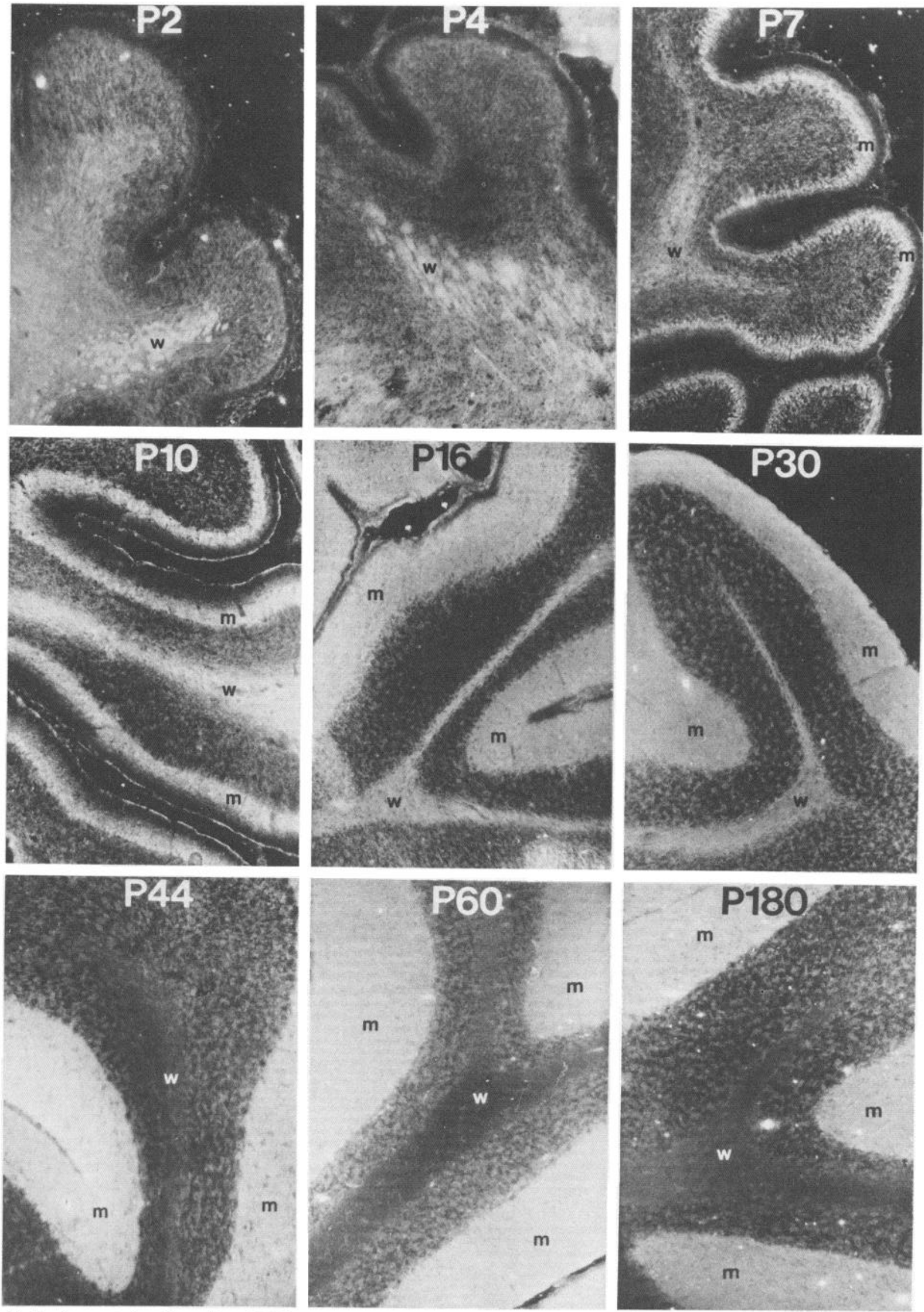

Figure 7. Development of staining with anti-NILE in the cerebellum. NILE immunoreactivity in the cerebellum was followed from P2 to P180. Staining in the white matter $(w)$ appears earlier than staining in the molecular layer $(m)$. However, staining of the white matter disappears during the 5th and 6th weeks whereas staining of the molecular layer persists. 

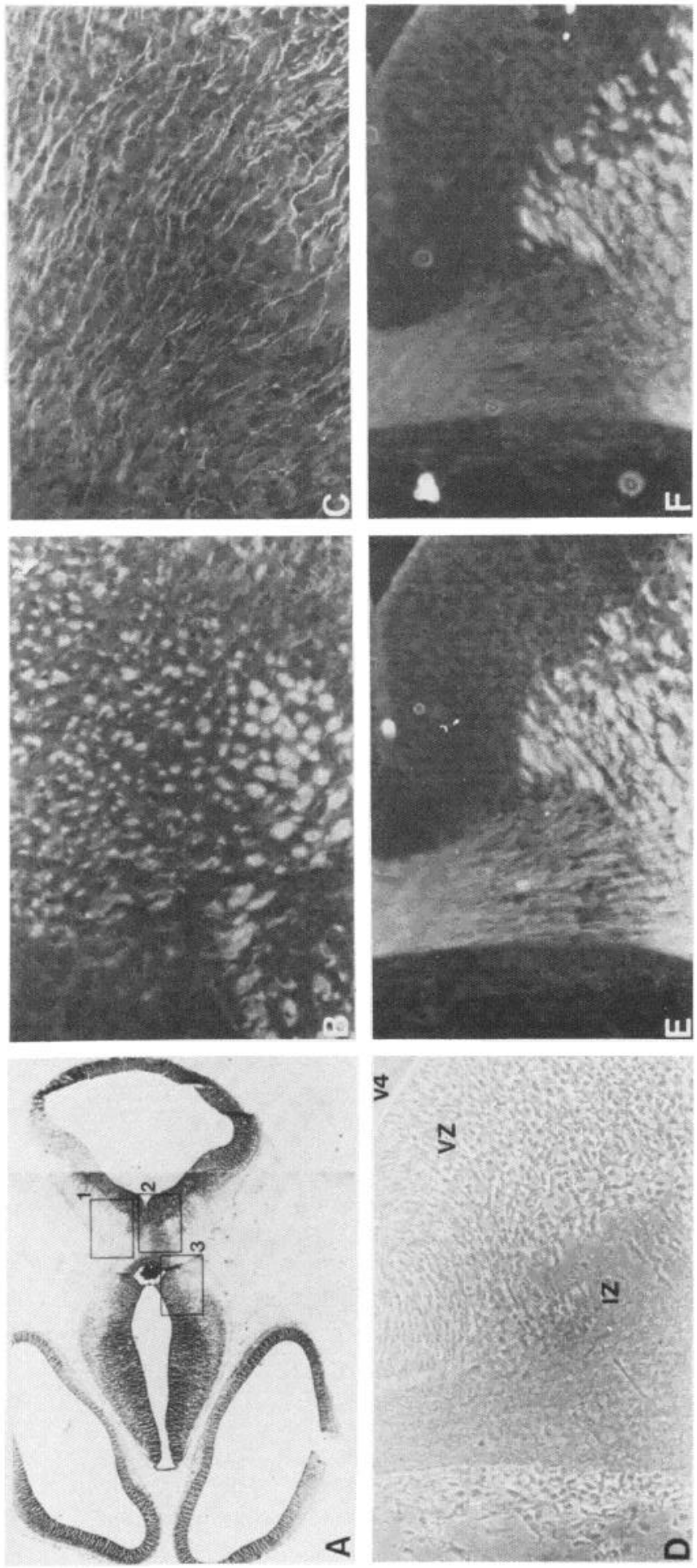
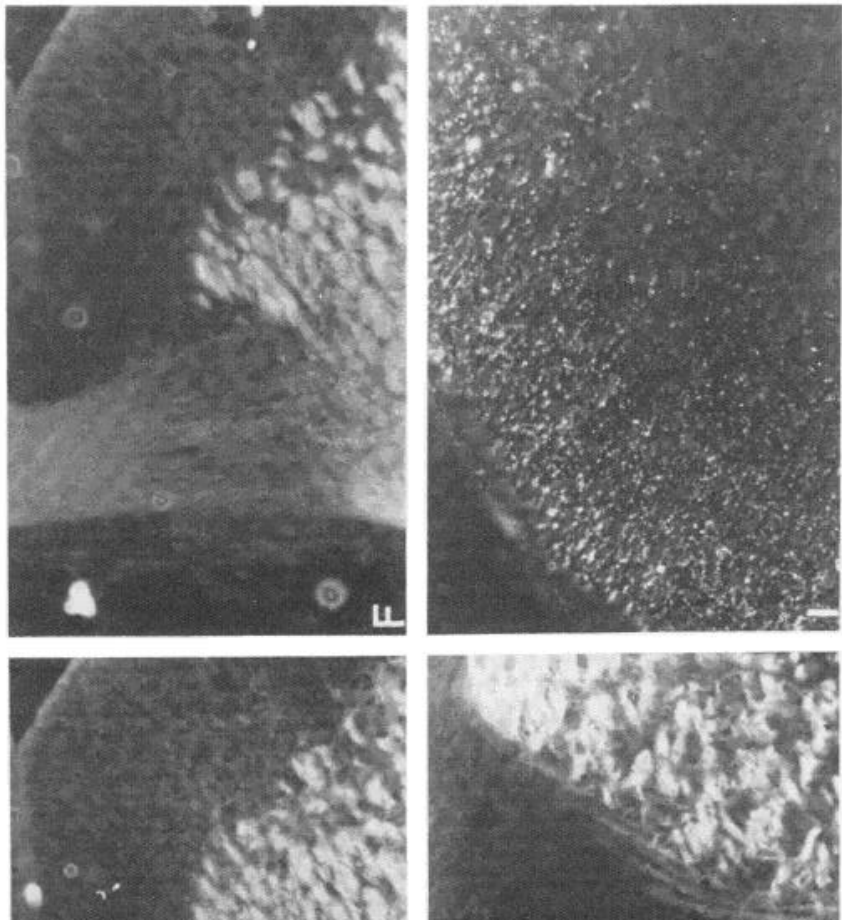

$\$$

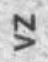

N

$s$

0
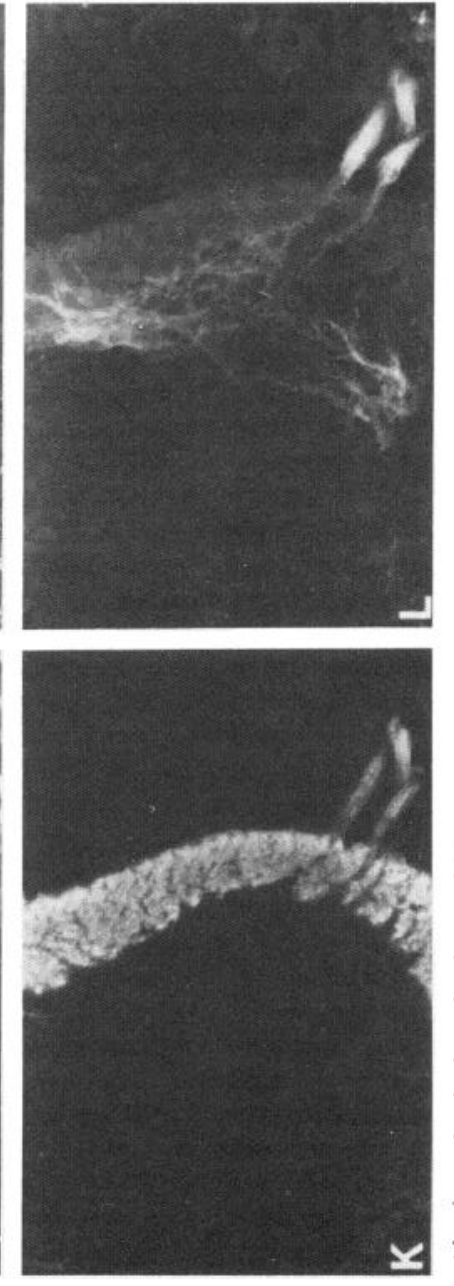

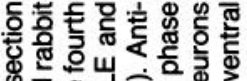

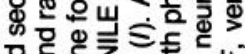

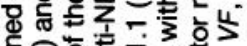

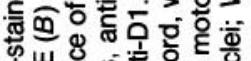

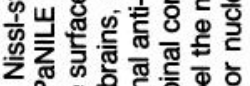
$\checkmark 00$

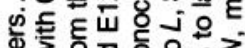

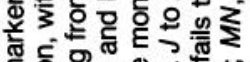
$\varepsilon$ 은

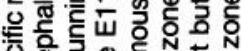
逐造

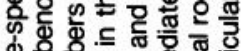
d 夏

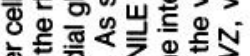

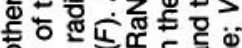

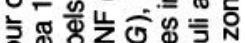
운

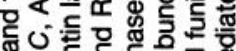
山⿰ 口屯 ๘

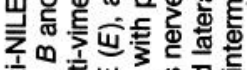

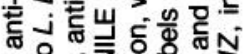
赵 든

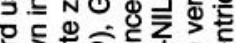

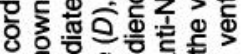
बक कि 的必

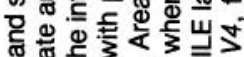
.

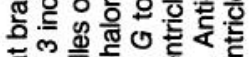

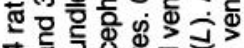

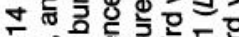

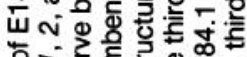
구응 क⿺辶

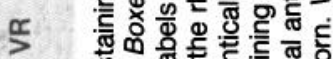
क.

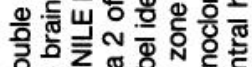

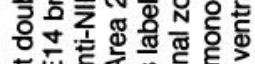

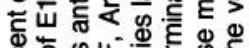

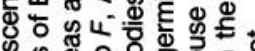
\&

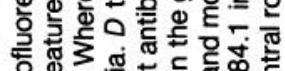

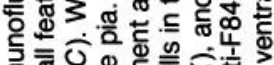

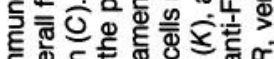

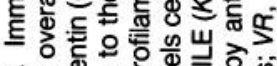
$\infty$ o

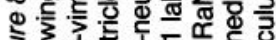

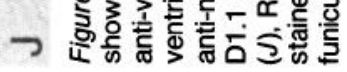


component is present in extracts of P30 rat brain (Salton et al. 1983b). Despite some superficial similarities, it can be shown that NILE-related glycoproteins are distinct from neural cell adhesion molecules (N-CAM; see Edelman, 1983). N-CAM and NILE compo nents have different electrophoretic mobilities on SDS-polyacrylamide gels, are immunologically distinct, and have different cellular distributions (Stallcup and Beasley, 1985b).

The results presented here demonstrate that antibodies against the NILE glycoprotein can be used to trace the development of axonal bundles or fiber tracts in the rat nervous system. The assertion that the anti-NILE antibody stains neuronal fiber tracts is based on the fact that it recognizes elements in tissue sections that are (1) identical to fiber tracts stained with antibody against neurofilament proteins but (2) distinct from the radial glial fibers stained by an antibody against the intermediate filament protein vimentin. The contrast between the distribution and appearance of neuronal and glial fibers detected by immunofluorescent staining with anti-NILE and anti-vimentin antibodies, respectively, was also seen in an earlier study which compared anti-neurofilament and anti-vimentin antibodies (Bignami et al., 1982). Although the level of resolution obtained with tissue sections at the light microscopic level does not allow us to distinguish between nerve fibers and closely associated glial elements, the results from tissue culture studies have demonstrated that both central and peripheral neurons express the NILE glycoprotein, whereas astrocytes and oligodendrocytes do not (Stallcup et al., 1983). Thus, in sections of central nervous tissue, which we have concentrated on here, the NILE glycoprotein is a marker for neuronal fiber tracts. Since Schwann celis also express the NILE glycoprotein, it is likely that both nerve fibers and Schwann cells contribute to the overall staining pattern observed in sections of peripheral nervous tissue.

Our evidence suggests that the NILE glycoprotein is not found on neuronal precursors or early neuroblasts, as illustrated by its absence on cells that express the D1.1 ganglioside. In the rat central nervous system the D1.1 marker is restricted to germinal cells found in well defined proliferative zones, i.e., primary proliferative zones surrounding the ventricles and secondary proliferative zones such as the external granule cell layer of the developing cerebellum (Levine et al., 1984). The failure of anti-NILE to stain precursor cells is not due simply to a lack of cellular extensions, because many of these germinal cells do extend processes. In the telencephalon, for example, the processes of ventricular germinal cells extend as far as the marginal zone, yet in our preparations these processes are not stained with anti-NILE. The NILE glycoprotein can first be detected on neurons that are presumably postmitotic. They have migrated away from the germinal zone and lost the D1.1 ganglioside, and they have extended axons into fiber bundles in the marginal and intermediate zones of the developing brain and spinal cord.

Our results indicate that the expression of NILE on differentiated neurons is not unitorm over the entire cell surface. Staining with antiNILE is not seen on neuronal cell bodies but appears to be largely restricted to axonal projections. The two clearest examples of this in tissue sections are found in structures associated with the spinal cord. First of all, in the spinal ganglion the cell bodies of sensory neurons are not noticeably stained by anti-NILE, whereas fibers within the ganglion and emerging from the ganglion in either direction are brightly stained. Second, the cell bodies and proximal parts of the axons of motor neurons in the ventral horn of the spinal cord are not stained by anti-NILE, whereas the motor efferents within the ventral root are brightly stained. Similar contrasts between the levels of NILE on the neurites and cell bodies of neurons in tissue culture have also been reported (Stallcup et al., 1983).

It has been repeatedly documented that neurogenesis does not occur simultaneously and uniformly throughout the nervous system but, rather, proceeds along different spatial and temporal gradients in different parts of the nervous system (Jacobson, 1978; Cowan, 1979). These conclusions regarding developmental gradients are most often cited with reference to the "birthdays" of neurons, as determined by $\left[{ }^{3} \mathrm{H}\right]$ thymidine autoradiography. Nevertheless, if there are developmental gradients of cell birth, it follows that there must also be gradients for subsequent events such as neuronal differentiation and fiber tract formation, although these secondary gradients may be distorted somewhat. With respect to the staining patterns seen with antibody against the NILE glycoprotein, developmental gradients appear to run in ventral to dorsal and caudal to rostral directions.

A ventral to dorsal gradient in the development of NILE-positive neuronal fiber tracts is somewhat apparent in the rhombencephalon, mesencephalon, and diencephalon of the rat. In each of these areas NILE-positive fibers in the marginal and intermediate zones can be seen in the more ventral of our horizontal sections 1 to 2 days earlier than in the more dorsal sections. A ventral to dorsal gradient is much more evident in the developing spinal cord. As illustrated by Windle and Baxter (1936b), the development of the ventral and lateral funiculi of the cord rather dramatically precedes that of the dorsal funiculus. The sequence and timing of events observed in this early paper by using the pyridine-silver method of staining neurofibrils are identical to those seen by immunofluorescent staining with anti-NILE antibody. The ventral and lateral funiculi can be seen as a continuous thin band of NILE immunoreactivity around the ventral half of the E11 spinal cord. Over the next few days this zone of stained fibers widens around the ventral and lateral surfaces of the cord. The precursor of the dorsal funiculus is first seen clearly at E12 as a very small zone of staining at the point of entry of the dorsal root just above the laleral funiculus. At this point there is no true dorsal funiculus, since the dorsal root entry zone is located laterally, but the NILE-positive entry zone gradually extends itself over the dorsal surface of the cord, finally covering the dorsal surface by E16 and invaginating to form the complete dorsal funiculus by E18.

With regard to the development of NILE immunoreativity along a caudal to rostral graident, NILE-positive fiber tracts are first seen at E11 in the spinal cord and rhombencephalon. Staining in the mesencephalon and diencephalon does not appear until 1 or 2 days later, and staining in the telencephalon is not seen until E15. An earlier study using the pyridine-silver staining method (Windle and Baxter, 1936a) also demonstrated that neurofibrillar development in the rat brain was first seen on E11 in the rhombencephalon. This was followed closely by the appearance of neurofibrils in the mesencephalon and diencephalon, much as we have described for the staining with anti-NILE antibody. Electron microscopic studies have shown that there are some fibers present in the marginal zone of the telencephalon at E15 and that fiber bundles begin to appear in the intermediate zone at E16 (Holmes and Berry, 1966). This is in good agreement with our finding that staining with anti-NILE first appears in the marginal zone of the telencephalon at E15 and in the intermediate zone at E16.

These observations on the timing of NILE appearance in various parts of the nervous system suggest that the NILE glycoprotein is present during the early stages of the development of fiber tracts. This concept is also supported by the fact that the development of staining with the anti-NILE antibody in a given area parallels very closely the development of staining with antibody against the three neurofilament proteins. Although the appearance of the 200,000 dalton neurofilament polypepide seems to be delayed during axon maturation (Shaw and Weber, 1982; Willard and Simon, 1983), the 70,000- and 150,000-dalton neurofilament polypeptides are expressed during the very early stages of axon development in many systems (Tapscott et al., 1981; Shaw and Weber, 1983). Thus, the NILE glycoprotein and two of the three proteins recognized by the anti-neurofilament antiserum, although distinct in terms of both their biochemistry and their location in nerve fibers, appear at very similar times during the early phases of fiber tract development (see Figs. 3 and 8 ).

In our experiments the NILE glycoprotein is immunohistochemically detectable in a given brain region only during a limited developmental period. As noted above, the appearance of NILE occurs 
during the major periods of prenatal fiber tract development in the spinal cord, rhombencephalon, mesencephalon, diencephalon and telencephalon. Following these periods, the antigen becomes in creasingly difficult to detcet immunohistochemically, and very little staining with anti-NILE can be seen by the end of the first week postnatally. This observation may explain the failure of other workers to find staining with anti-NILE antibody in fixed sections of rat nervous tissue (Salton et al., 1983a). In contrast, the NILE glycoprotein is easily detectable postnatally in structures such as the olfactory bulb and cerebellum, which undergo major phases of neurogenesis after birth (Hinds, 1968a; Altman, 1969, 1972a, b). Because of the relatively detailed understanding of the cellular development and architecture of these two areas, they provide additional insight into the timing of NILE glycoprotein expression.

Two zones of NILE immunoreactivity are seen in the postnatal cerebellum. The white matter is stained with anti-NILE at P2 and P4, the earliest cerebellar tissue we examined, whereas staining of the molecular layer is not apparent until P7. These observations are consistent with current knowledge concerning the development of the fiber structure of these two layers. The white matter contains fibers, including efferent Purkinje cell axons and various cerebellar afferent fibers, which begin development prenatally (Addison, 1911; Sidman, 1968; Das and Nornes, 1972; Shimono et al., 1976; Mariani and Changeux, 1981). In contrast, the molecular layer contains the dendrites of Purkinje cells, the processes of stellate and basket neurons, and the parallel fibers of granule neurons, all of which develop primarily during the second and third postnatal weeks (Altman, 1969, 1972a, b). It is tempting to speculate that the parallel fibers of granule cells might contribute heavily to the anti-NILE staining, since they are packed tightly together in the molecular layer much like axons in a fiber tract. At any rate, as in other areas of the brain, anti-NILE staining of the white matter is only seen over a finite period of time. Staining disappears during the fifth and sixth postnatal weeks. In contrast, staining of the molecular layer persists into adulthood.

The olfactory nerve, like the cerebellar molecular layer, is stained by anti-NILE antibody over a much longer time span than other fiber tracts we have considered. It is brightly stained by anti-NILE as early as $E 13$ when it first reaches the olfactory bulb (Hinds, 1968b). As shown in Figure $6 F$, it is still brightly labeled at P7, and we have seen staining at the age of 2 months (not shown). What determines whether NILE immunoreactivity disappears or persists in a given fiber tract? Is there actual down regulation of the level of NILE on nerve fibers or is there a process which results in the masking of NILE? The following observations may be relevant to these questions.

One characteristic of the olfactory nerve that distinguishes it from many other nerve fiber tracts is that it remains unmyelinated (Shepherd, 1972), and we have considered the possibility that this could explain the persistence of staining with anti-NILE. Perhaps an intact myelin sheath masks the NILE glycoprotein so that it cannot be recognized by antibody. This idea is supported by the pattern of myelination in the cerebellum. Very few of the fibers of the rat cerebellar molecular layer become myelinated, whereas in the white matter the Purkinje axons, the climbing fibers, and the mossy fibers are all myelinated (Palay and Chan-Palay, 1974). This is in excellent agreement with our finding that anti-NILE staining persists in the molecular layer and disappears in the white matter. With regard to other fiber tracts it seems likely that most of the ones we have examined in the rat spinal cord and brain becomes myelinated, although it may well be asked whether sufficient myelination has occurred during the first week postnatally to explain the loss of staining that we have oberved. In the spinal cord myelination may begin by $\mathrm{P} 2$ or $\mathrm{P} 3$, but in most areas of the brain myelination does not reach its peak until the second week postnatally (Jacobson, 1978). Thus, the hypothesis that myelination may be responsible for masking the NILE glycoprotein is an attractive one, but the evidence at present is only circumstantial.
We have recently described a series of experiments which suggest that the NILE glycoprotein is involved in the fasciculation of neurites in primary cultures of E14 rat brain (Stallcup and Beasley, 1985a). Fab' fragments of antibody against the NILE glycoprotein almost completely inhibited the formation of neurite bundles in these cultures. By comparison, Fab' fragments of antibody against $\mathrm{N}$ CAM, which has been shown to be involved in the fasciculation of neurites in cultures of chick spinal ganglia (Rutishauser et al., 1978), had a very small effect on fasciculation in the cultures of embryonic rat brain. The NILE glycoprotein may therefore be the principal mediator of neurite fasciculation for neurons derived from embryonic rat brain. Our findings that the NILE glycoprotein (1) is located primarily on neurites not only in vitro but also in vivo and (2) appears on neurites during the early phases of fascicle formation in vivo show that NILE may also play a role in the process of fasciculation in vivo.

\section{REFERENCES}

Addison, W. (1911) The development of the Purkinje cells and of the cortical layers in the cerebellum of the albino rat. J. Comp. Neurol. 21: 459-488.

Akeson, R. and W. Hsu (1978) Identification of a high molecular weight nervous system specific cell surface glycoprotein on murine neuroblastoma cells. Exp. Cell Res. 115: 357-377.

Altman, J. (1969) Autoradiographic and histological studies of postnatal neurogenesis. III. Dating the time of production and onset of differentiation of cerebellar microneurons. J. Comp. Neurol. 136: 269-294.

Altman, J. (1972a) Postnatal development of the cerebellar cortex in the rat. I. The external germinal layer and the transitional molecular layer. J. Comp. Neurol. 145: 353-397.

Altman, J. (1972b) Postnatal development of the cerebellar cortex in the rat. II. Phases in the maturation of Purkinje cells and of the molecular layer. J. Comp. Neurol. 145: 399-464.

Bignami, A., T. Raju, and D. Dahl (1982) Localization of vimentin, the nonspecific intermediate filament protein, in embryonal glia and in early differentiating neurons. Dev. Biol. 91: 286-295.

Bulloch, K., W. B. Stallcup, and M. Cohn (1977) The derivation and characterization of neuronal cell lines from rat and mouse brain. Brain Res. 135; 25-26.

Cowan, W. (1979) Selection and control in neurogenesis. In The Neurosciences: Fourth study Program. F. Schmitt and F. Worden, eds., p. 59-79, MIT Press, Cambridge, MA.

Dahl, D. (1981) Isolation of neurofilament proteins and of immunologically active neurofilament degradation products from extracts of brain, spinal cord, and sciatic nerve,. Biochim. Biophys. Acta 668: 299-306.

Das, G., and H. Nornes (1972) Neurogenesis in the cerebellum of the rat: An autoradiographic study. Z. Anat. Entwicklungsgesch. 138: 155-165.

Edelman, G. (1983) Cell adhesion molecules. Science 219: 450-457.

Greene, L., and A. Tischler (1976) Establishment of a noradrenergic clonal line of rat adrenal pheochromocytoma cells which respond to nerve growth factor. Proc. Natl. Acad. Sci. U. S. A. 73: 2424-2428.

Hinds, J. (1968a) Autoradiographic study of histogenesis in the mouse olfactory bulb. I. Time of origin of neurons and neuroglia. J. Comp. Neurol. 134: $287-304$.

Hinds, J. (1968b) Autoradiographic study of histogenesis in the mouse olfactory bulb. II. Cell proliferation and migration. J. Comp. Neurol. 134; 305-322

Holmes R., and M. Berry (1966) Electron microscopic studies on developing foetal cerebral cortex of the rat. In Evolution of the Forebrain, R. Hassler and H. Stephan, eds., pp. 206-212, Verlag, Stuttgart.

Jacobson, M. (1978) Developmental Neurobiology, Plenum Press, New York. Lee, V., L. Greene, and M. Shelanski (1981) Identification of neural and adrenal medullary surface membrane glycoproteins recognized by antisera to cultured rat sympathetic neurons and PC12 pheochromocytoma cells. Neuroscience 6: 2773-2786.

Levine, J. M., L. Beasley, and W. B. Stallcup (1984) The D1.1 antigen: A cell surface marker for germinal cells of the central nervous system. J. Neurosci. 4: 820-831.

Mariani, J., and J. -P. Changeux (1981) Ontogenesis of olivocerebellar relationships. I. Studies by intracellular recordings of the multiple innervation of Purkinje cells by climbing fibers in the developing rat cerebellum. J. Neurosci. 1: 696-702.

McGuire, J., L. Greene, and A. Furano (1978) NGF stimulates incorporation 
of fucose or glucosamine into an external glycoprotein in cultured rat PC12 pheochromocytoma cells. Cell 15: 357-365.

Palay, S., and V. C. Chan-Palay (1974) Cerebellar Cortex Cytology and Organization, Springer-Verlag, New York.

Rutishauser, U., W. Gall, G. Edelman (1978) Adhesion among neuronal cells of the chick embryo. IV. Role of the cell surface molecule CAM in the formation of neurite bundles in cultures of spinal ganglia. J. Cell Biol. 79: $382-393$.

Salton, S., C. Richter-Landsburg, L. Greene, and M. Shelanski (1983a) Nerve growth factor-inducible large external (NILE) glycoprotein: Studies of a central and peripheral neuronal marker. J. Neurosci. 3: 441-454.

Salton, S., M. Shelanski, and L. Greene (1983b) Biochemical properties of the nerve growth factor-inducible large external (NILE) glycoprotein. J. Neurosci. 3: $2420-2430$.

Schnitzer, J., W. Franke, and M. Schachner (1981) Immunocytochemical demonstration of vimentin in astrocytes and ependymal cells of developing and adult mouse nervous system. J. Cell Biol. 90: 435-447.

Schubert, D., S. Heineman, W. Carlisle, H. Tarikas, B. Kines, J. Patrick, J. H. Steinbach, W. Culp, and B. L. Brandt (1974) Clonal cell lines from the rat central nervous system. Nature 249: 224-227.

Shaw, G., and K. Weber (1982) Differential expression of neurofilament triplet proteins in brain development. Nature 298: 277-279.

Shaw, G., and K. Weber (1983) The structure and development of the rat retina: An immunofluorescence microscopical study using antibodies specific for intermediate filament proteins. Eur. J. Cell Biol. 30: 218-232.

Shepherd, G. M. (1972) Synaptic organization of the mammalian olfactory bulb. Physiol. Rev. 52: 864-917.
Shimono, T., S. Nosaka, and K. Sasaki (1976) Electrophysiological study on the postnatal development of neuronal mechanisms in the rat cerebellar cortex. Brain Res. 108: 279-294.

Sidman, R. (1968) Development of interneuronal connections in brains of mutant mice. In Physiological and Biochemical Aspects of Nervous Integration, F. Carlson, ed., pp. 163-193, Prentice-Hall, Inc., Englewood Cliffs, NJ.

Stallcup, W. B., and L. Beasley (1985a) Involvement of the NILE glycoprotein in neurite fasciculation in primary cultures of rat brain. Proc. Natl. Acad. Sci. U. S. A., in press.

Stallcup, W. B., and L. Beasley (1985b) Polymorphism among NILE-related glycoproteins from different types of neurons. Brain Res., in press.

Stallcup, W. B., L. Arner, and J. Levine (1983) An antiserum against the PC12 cell line defines cell surface antigens specific for neurons and Schwann cells. J. Neurosci. 3: 53-69.

Tapscott, S., G. Bennett, Y. Toyama, F. Kleinbart, and H. Holtzer (1981) Intermediate filament proteins in the developing chick spinal cord. Dev. Biol. 86: 40-54.

Willard, M., and C. Simon (1983) Modulation of neurofilament axonal transport during the development of rabbit retinal ganglion cells. Cell 35: 551-559.

Windle, W., and R. Baxter (1936a) The first neurofibrillar development in albino rat embryos. J. Comp. Neurol. 63: 173-187.

Windle, W., and R. Baxter (1936b) Development of reflex mechanisms in the spinal cord of albino rat embryos. Correlations between structure and function, and comparisons with the cat and the chick. J. Comp. Neurol. 63: $189-209$. 